\title{
38. COMMISSION POUR L'ECHANGE DES ASTRONOMES
}

\section{Président: F. J. M. Stratton.}

Membres: MM. Abetti, Bowen, Chang, Danjon, Dawson, Minnaert, Mohr, Nassau, Petrie, Rosseland, Shane, Stoy, Struve, Swings, Unsöld, Witkowski, Woolley.

There has been a marked increase in the number of applications for grants received in the last three years. Whereas in the previous three years grants were made for fourteen astronomers $(34-47)$, in the three years covered by this report grants have been made for twenty-two astronomers $\left(4^{8}-69\right)$. They are as follows:

48. A Belgian astronomer to several observatories in the U.S.A.

49. A Japanese astronomer to Paris and Utrecht.

5o. An Italian astronomer to Liège and Paris.

51. A Greek astronomer to Meudon and the Pic-du-Midi.

52. A Dutch astronomer to work at Mount Palomar Observatory and to visit other observatories in the U.S.A.

53. A Greek astronomer to Arcetri Observatory.

54. A Canadian astronomer to Liège.

55. An American astronomer to Liège.

56. An Italian astronomer to the Leuschner Observatory, Berkeley, California.

57. A Greek astronomer to Cambridge, England.

$5^{8}$. A British astronomer to Liège.

59. An Indian astronomer to Lille.

6o. An Argentinian astronomer to Mount Wilson and Lick.

6r. An American astronomer to Liège.

62. A French astronomer to Yerkes and Climax.

63. A British astronomer to the Canary Isles.

64. A British astronomer to Yerkes and the Smithsonian Astrophysical Observatories.

65. A Norwegian astronomer to Yerkes.

66. A German astronomer to Herstmonceux.

67. A Greek astronomer to Meudon.

68. A Polish astronomer to the Institut d'Astrophysique, Paris.

69. A Japanese astronomer to Paris.

Grants have been promised to two astronomers for $195^{8}$ :

70. A Czechoslovak astronomer to Manchester.

71. A Czechoslovak astronomer to Marseilles and Haute Provence.

The visits of astronomers from fifteen different countries to foreign observatories or institutes have been made possible by grants in aid from the Commission. In two cases on the strong recommendation of the director of the observatory concerned, a second grant was made to the same individual. One important reason lying behind a number of applications was to secure an opportunity of working with larger instruments than those available in the applicant's own country or to secure material that could be studied at leisure later at home. Reports received from those in receipt of grants indicated that they had made good use of the facilities placed at their disposal. Opportunities also in many cases were offered to visiting astronomers to attend colloquia and symposia and to meet experts in a special line of research or to consult libraries for research purposes.

A wide range of subjects was covered by the visiting astronomers, including:

Meridian astronomy. Observations of Mars at opposition. Stellar statistics. Galactic research and classification of galaxies. Molecular spectra. Infra-red spectroscopy. Carbon $\mathrm{C}$ stars. Stars with emission lines in their spectra. Wolf-Rayet stars and individual stars, e.g. 


\section{COMMISSION 38}

$\beta$ Lyrae. Cepheid variables: curves of growth and equivalent widths at different phases. Photo-electric photometry. Stellar models. Transfer of radiation. Chromospheric granulation. Cosmical gas dynamics. Interference filters. Local conditions for observing a coming total eclipse.

The general principles covering grants remained the same. An applicant must be supported by a responsible astronomer in his own country. He, and also his proposed programme of work, must be accepted by the head of the Institution he wishes to visit. In general, part of the total expense of travel and maintenance should come from other sources: the grant should be regarded rather as a supplementary grant to meet the financial gap left by other grants available in either of the two countries concerned.

With the consent of the bureau of the Union, grants were made from the Commission's funds to help young astronomers to attend the General Assembly of the Union at Dublin. It has been suggested that at the coming General Assembly the question should be discussed of making more generally known what facilities exist at different observatories in the way of research fellowships, etc. On this point reference can be made to the lists in Trans. I.A.U. 7, 4I 4. Regulations for guest investigators at the Mount Wilson and Mount Palomar observatories can now be obtained from the Director. As explained above arrangements are generally made between the applicant or his Director, and the Director of the observatory or institution to be visited, before an application is made to the Commission.

During the three years I955-57 grants made to individuals totalled $\$ \mathrm{I}_{5}$ Iog.8I in addition to a grant of $\$ 4546 \cdot 37$ for young astronomers attending the Dublin meeting. The balance in hand at the end of I957 is \$IOgr.06. It is clear that to keep up the present rate of grants an increase of the annual allocation from the funds of the Union to a sum of $\$ 5000$ a year is desirable, provided funds are available.

F. J. M. STRATTON

President of the Commission

\section{Report of Meeting. I4 August 1958}

President: F. J. M. Stratton.

SeCRETARY: B. J. Bok.

The meeting of Commission 38 opened with the President explaining that the difference between the balances in hand as shown on pages 48 and 592 was simply due to the fact that they referred to the different dates 3I October and 3I December respectively. The President then presented the following Supplementary Report:

The two grants mentioned in the Report of the Commission as promised to Czechoslovakian astronomers $(70,7 \mathrm{I})$ have now been made.

Further grants have also been made as follows:

72. A French astronomer to Asiago.

73. A Spanish astronomer to Cambridge, England.

74. A British astronomer to Madrid and Tenerife.

Three further applications are still pending. One further grant for 1959 has been promised.

75. A Czechoslovakian astronomer to Mexico and Mount Palomar.

A grant of $\$ 1000$ was made to help young astronomers to attend the General Assembly of the Union at Moscow in $195^{8}$.

The Draft Report and the Supplementary Report were adopted unanimously and without change. In moving the adoption of the Report Professor P. Swings expressed the gratitude of all astronomers to Professor J. F. M. Stratton for the excellent work that he had done for many years in the field of exchanges of astronomers. The world-wide community of astronomers has profited greatly from the wise administration of the exchange programme by Professor Stratton. 


\section{ECHANGE DES ASTRONOMES}

In view of the increase in the number of applications, and the excellence of the results obtained to date, the meeting adopted a motion to apply for an annual grant of $\$ 6000$ for each of the coming years, I959, I960 and I96r. The Secretary was asked to transmit this recommendation promptly to the General Secretary.

Three recommendations from members of the Commission were considered. Professor M. G. J. Minnaert had suggested that the Commission should prepare a statement of Fellowships and other means of support available at different institutions and in different countries, and Professor J. J. Nassau had similarly suggested that lists be prepared of institutions interested in receiving applications, and that these lists be published in several journals. Professor Minnaert had further suggested that special attention be paid to the encouragement of East and West exchanges.

The meeting decided to consider together the first of Professor Minnaert's recommendations and Professor Nassau's recommendation. After considerable discussion, it was decided that the President of Commission 38 be empowered to appoint a small Committee to assist him in the gathering of the required information. It was felt that this should not be necessarily an occasion for the circulation of an elaborate questionnaire, but that more meaningful data could be gathered in a rather informal manner by suitably chosen regional representatives. It was suggested that President Stratton, with the assistance of his advisers, should prepare a fairly extensive Report. Professor Bok suggested that it should include detailed information about the individuals to whom applications should be made in each case. This Report should be circulated to all observatories and a summary should be published in the leading astronomical journals.

There was general agreement that every effort should be made to promote East-West exchanges under the auspices of Commission 38. In this connexion $\mathrm{Dr} R$. M. Petrie mentioned the Canadian Doctoral Fellowship Programme now administered by the Canadian National Research Council. Applications are welcomed under this Programme from nationals of all countries and the only requirement of eligibility is that the candidate should satisfy the Canadian Immigration requirements.

The final item on the Agenda for the meeting related to the travel of younger astronomers to international symposia. The President of Commission 38 was urged to experiment in the years to come on a modest scale with support of young astronomers qualified and interested to attend specific international symposia. 